\title{
酸性モリブデン酸リチゥム水溶液から還元析出する エレクトロクロミックな青色電着物の組成および析出状態
}

\author{
西山 直樹*，森崎 重喜，馬場 宣良
}

The Morphology and Composition of the Electrochromic Blue Deposits Electrodeposited on the Cathode from Acidic $\mathrm{Li}_{2} \mathrm{MoO}_{4}$ Aqueous Solutions

Naoki NISHIYAMA*, Shigeyoshi MORISAKI and Nobuyoshi BABA

Received December 25, 1989 ; Accepted March 2, 1990

\begin{abstract}
The electrochromic blue deposits electrodeposited on the cathode from $\mathrm{Li}_{2} \mathrm{MoO}_{4}$ aqueous solution of $\mathrm{pH} 1$ were investigated by thermalanalysis, elementary analysis, X-ray diffraction pattern, and IR spectra. The deposits were amorphous and contained water. The deposits were composed of about $98 \%$ by $\mathrm{Li}$, Mo and 0 , so the deposits were colybdenum oxide containing Li. By heat treatment, the adsorbed and combined water was removed, while a large quantity of $\mathrm{MOO}_{3}$ and a small quantity of $\mathrm{MoO}_{2.8}, \mathrm{MO}_{8} \mathrm{O}_{28}$ was crystallized. Over $700^{\circ} \mathrm{C}$, most of the deposits were sublimed. The eapirical formula of dehydrated deposits was $\mathrm{Li}_{0 .} \mathrm{MM}^{\mathrm{M}} \mathrm{O}_{3} . \mathrm{O}$. It agreed with blue colored state in electrochronism of $\mathrm{MoO}_{3}$. In conclusion, the deposits were $\mathrm{MOO}_{3}$ in the mixed state of 5 valence and 6 valence containing a very small amount of Li. A part of molybdenum atoms was reduced to 5 valence state.
\end{abstract}

\section{1.粕言}

近年，エレクトロクロミック材料（以下E Cと略す） としての造移金原酸化物薄黄が注目されている。 E C 材 料は䬺明で明るい色を示すことや，視角依存がないこと などから瘦晶に代わる表示素子として期待され研究が進 められてきた。しかし，度答があまり速くないことから

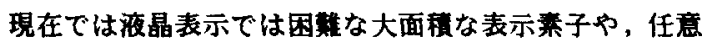
に色の浱さがコントロールできること，メモリー性のあ ることなどを利用した调光がラスへの応用が考えられて

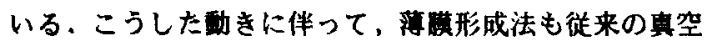

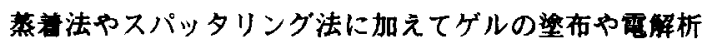
出法などの大面转の工業製品を作憋するのに適した方法

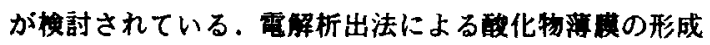
は，低コストで大面程なものがつくれること，析出する 薄嗼の莫厚を雨荷量によって制梅できることなどから大

東京都立大学工学部工業化学科 ( T158 東京都世田谷区 深沢 2-1-1) Departuent of Industrial Chenistry, Faculty of Technology, Tokyo Metropolitan University (2-1-1 Fukasawa, Setagaya-ku, Tokyo 158) Key Words: Electrochromisa, Molybdenue oxide Electrodeposition
いに注目される。これまでに $\mathrm{V}_{2} \mathrm{O}_{5}{ }^{1.2)}, \mathrm{MnOx}^{3 \cdot 4)}$,

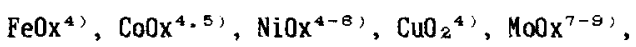
$\mathrm{Ru} 0 \mathrm{x}^{10}, \mathrm{WOX}^{11)}, \mathrm{ReO \textrm {x } ^ { 1 2 }}, \mathrm{Ir} 0 \mathrm{x}^{13)}, \mathrm{WO}_{3}+\mathrm{MOO}_{3}$ 膜 $\left.^{24}\right)$ など多くの遷移金属酸化物が雷解析出法で薄䐵形成され ることが報告されている。これらのうち $V_{2} 0_{5}{ }^{1.23}$ ， $\mathrm{MnOx}^{3)}, \mathrm{NiOx}^{8)}, \mathrm{MoOx}^{7)}, \mathrm{Ir} 0 \mathrm{x}^{13)}$ でェレクトロクロミ ズムを示すことが報告されている.我々はpH拥整した モリブデン䣬堭水溶液中で雪解迡元することによって p H0.7〜1.5では争色↔無色のエレクトロクロクロミ

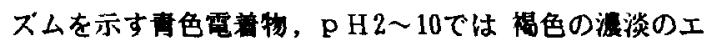
レクトロクロミズムを示す神色電着物が蒋黄形成される ことを見出し，そのエレクトロクロミック特性”や電解 条件の影䈏15にについてすでは埌告した。この論文では 整分析，定量分析および枌末X線回折パターン，赤外吸 収スペクトルの洞定を行なって，良好な青色な無色の エレクトロクロミック特性を有する青色面羊物について の检討結果を埌告する。

\section{2. 实}

\section{1 诫科作罠}

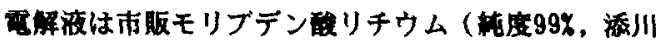
理化学製）を茶留水に浱度0.5M( $\left(\mathrm{M}=\mathrm{nol} / \mathrm{d}^{3}\right)$ となる 
ように澄解し，碳酸で溶液のpHが 1 となるように調整 した.

アノード,カソード共にNESAガラス (11.18/ロ,

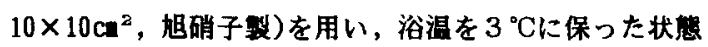
で、マグネチックスターラーで浴を港拌しながら定電流

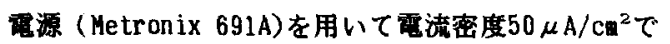
$3 \sim 4$ 時間定電流電解を行ない，厚く析出した青色電諸 物を蒸留水で十分に水洗し，䡉樭することによって N E S Aガラスより剥新させたものをメノウ钵で粉碎し， 测定用武料とした。

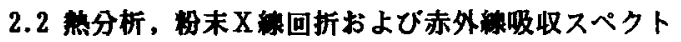
ルの沟定，定量分析

電着物の熱分析は示差熱熱重量同時湖定装篟（セイコ 一電子工業 T G / D T A 300)をデーター処理装置(セ イコー電子工業 S S C-500)に接繶して, 昇温速度

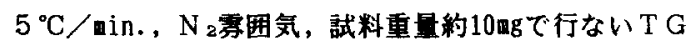
一D T A曲線を得た。

また，いくつかの温度で就処理を行ない，それぞれの 試料について，粉末X線回折パターンをX線回折装置

（理学電機製）によって, 赤外線吸収スペクトルを赤外 分光光度計 (島津製作所 I R-440型) を用いてKB r 錠剂法によって測定し，Li，MoをI C P 発光分析装 置（セイコ一電子工業 S T S $1200 \mathrm{~A}$ ），Oを䣹素-窒 素分析装是（堀埸製作所製）を用いて定量した。

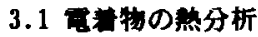

\section{3. 結果}

電着物の T G - D T A曲線㴬定秙果をFig.1に示した. $200^{\circ} \mathrm{C}$ 付近までに脱水によると考えられるブロードな吸 愁ピークと共に連続的な重量減少がみられた。この時の 重量減少は試料量の14.2\%であった。 $269^{\circ} \mathrm{Cから} 323^{\circ} \mathrm{C} に$

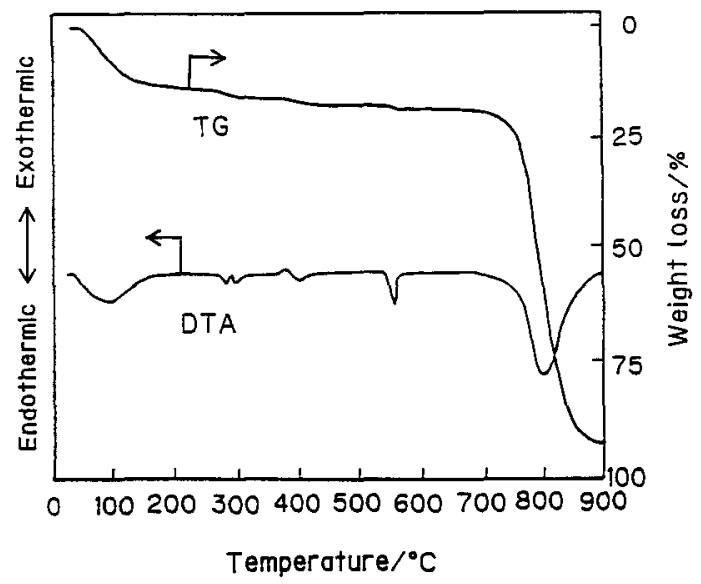

Fig. 1 TG-DTA curves of the electrodeposits from $\mathrm{Li}_{2} \mathrm{MOO}_{4}$ aqueous solution adjusted at $\mathrm{pH} 1$ by $\mathrm{H}_{2} \mathrm{SO}_{4}$.
かけて吸熟反応を示し，この間に2.1\%の重量城少が見 られた。 $292^{\circ} \mathrm{C} に$ 発熱ピークが挌められた。 $382^{\circ} \mathrm{C} に$ 発 热ピークの後 $419^{\circ} \mathrm{C}$ まて吸第反応を示し，この時 $1.4 \% の$

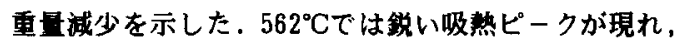
1.2\%の重量娍少があった。 $700^{\circ} \mathrm{C}$ 付近から重量娍少し始 め，750 $\mathrm{C}$ 付近からは大きな吸热反応を示し大きく重量

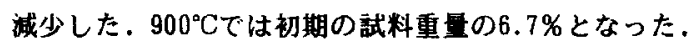

\section{2 赤外吸収スベクトル}

各热処理温度における電諳物の赤外線吸収スペクトル をFig.2に示した。何も処理をしていない雷着物の赤外 吸収スペクトル図は約 $3400 \mathrm{~cm}^{-1} に \mathrm{H}_{2} 0$ 分子の0-H伸籍振 動による吸収帯, 約 $1620 \mathrm{~cm}^{-1}$ に $\mathrm{H}_{2} \mathrm{O}$ 分子のH一OーH変角振 動による吸収帯がみられた。また，約 $960 \mathrm{~cm}^{-1}$ ，約560

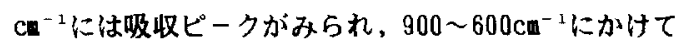
$720 \mathrm{c}^{-1}$ にピークを持つブロードな吸収带がみられた。

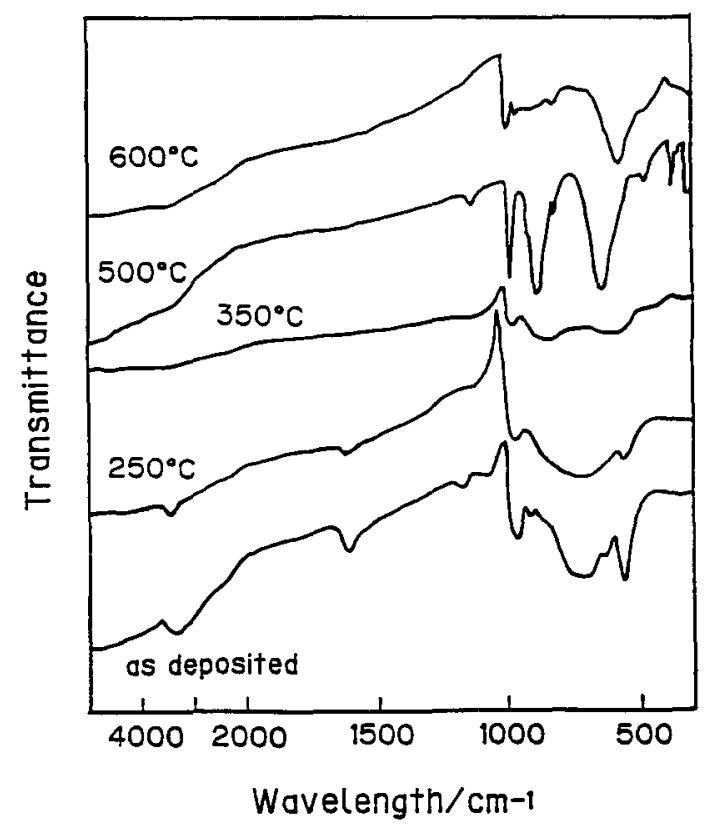

Fig.2 IR spectra of the electrodeposits from $\mathrm{Li}_{2} \mathrm{MoO}_{4}$ aqueous solution adjusted at pH 1 by $\mathrm{H}_{2} \mathrm{SO}_{4}$.

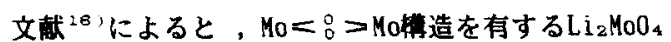

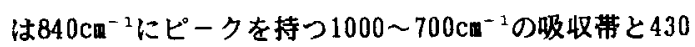
$\mathrm{cm}^{-1}$ 付近にピークを持つ550〜350 $\mathrm{cm}^{-1}$ の吸収带が見られ，

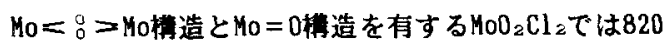
$\mathrm{cm}^{-1}$ にピークを持つ900〜 700 $\mathrm{cm}^{-1}$ の吸収带, $380 \mathrm{~cm}^{-1}$ に ピークを持つ400〜 350 $\mathrm{cm}^{-1}$ の吸収带の他, $970 \mathrm{~cm}^{-1}$ にピ 一クを持つ1000〜950 $\mathrm{cm}^{-1}$ の吸収带が現れる.さらに, $M_{0}<:>M_{0}$ 槽造, $M_{0}=0$ 榑造, Mo-0ーMo榑造を有する

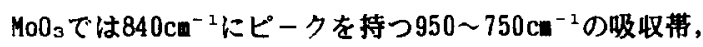
$370 \mathrm{~cm}^{-1}$ にピークを持つ400〜350 $\mathrm{cm}^{-1}$ の吸收带, 1000 
$\mathrm{ca}^{-1}$ にビークを持っ1010〜960 $\mathrm{cm}^{-1}$ の吸収费の他，540 $\mathrm{cm}^{-1}$ 付近にピークを持つ700〜 450 $\mathrm{cm}^{-1}$ に喛収曹が現れる. これらのことから考えられる槽造と吸収の閶係をTable 1にまとめた。

Table 1 IR absorption bands of molybdenum compounds and their assignments.

\begin{tabular}{cc}
\hline$\lambda / \mathrm{cm}^{-1}$ & Assignaent \\
\hline $1010 \sim 950$ & $\nu\left(M_{0}=0\right)$ \\
$950 \sim 700$ & $\nu a s\left(M_{0}<:>M_{0}\right)$ \\
$700 \sim 450$ & $\nu=\left(M_{0}-0-M_{0}\right)$ \\
$450 \sim 350$ & $\delta\left(M_{0}<:>M_{0}\right)$ \\
\hline
\end{tabular}

Table 1より，何も処理をしていない電羊物の赤外吸

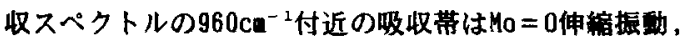

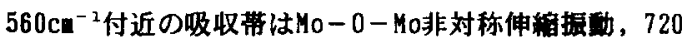
$\mathrm{cs}^{-1}$ 付近のブロードな吸収带は $M 0<:>M_{0}$ 非刘称伸縮振

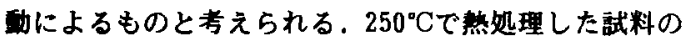
赤外吸収スペクトル図では何の処理もしない竜看物に比 べて， $\mathrm{H}_{2}$ O分子に起因する約 $3400 \mathrm{~cm}^{-1}$ 付近と約 $1620 \mathrm{~cm}^{-1}$ 付近の吸收が小さくなり, $960 \mathrm{~cm}^{-1}, 560 \mathrm{~cm}^{-1}$ 付近の吸収 带も小さくなった。 $350^{\circ} \mathrm{C}$ 熟処理武料のスペクトル戉は 全体的に吸収が小さくなり，980 $\mathrm{cm}^{-1}$ 付近, $850 \mathrm{~cm}^{-1}$ 付近, $650 \mathrm{~cm}^{-1}$ 付近にブロードな吸收がわすかにみられた。 500 ${ }^{\circ} \mathrm{C}$ 热処理試料では多くのはっきりとした吸收が現れ， $M 0=0$ 伸繶振動の $995 \mathrm{~cm}^{-1}, M 0<{ }_{0}^{0}>M o$ 非対称伸綰振動の $895 \mathrm{~cm}^{-1}$ ，Mo-0-Mo非対称伸編层動の650 $\mathrm{cm}^{-1}$,

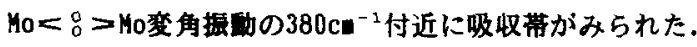
$600^{\circ} \mathrm{C}$ 然処理試料で注 $500^{\circ} \mathrm{C}$ 整処理試料での895 $\mathrm{cm}^{-1}$ ， $380 \mathrm{~cm}^{-1}$ の吸収带が消失し, $995 \mathrm{~cm}^{-1}, 575 \mathrm{~cm}^{-1}$ に吸収带 が見られた。

\section{3 暗末回折パターン}

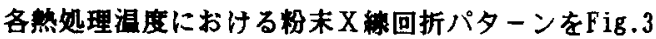
に示した、何も処理をしていない霓养物および $250^{\circ} \mathrm{C}$ 熱 処理した試科で仙明礁な回折ピークをもたないハローパ ターンとなった. $350^{\circ} \mathrm{C}$ 繁処理試料の回折パターン図で は回折ピークが現れ，これらのピークのすべて $\mathrm{MoO}_{3}$ の回 折ピークと一致した. $500^{\circ} \mathrm{C}$ 烸処理武料では, 回折ピー クの強度がより大きく明穛となった，回折ピークはほと んどが $\mathrm{HoO}_{3}$ の回折ピークと一致したが，一部 $\mathrm{MoO}_{2.8}$ の ピークがみられた。 $600^{\circ} \mathrm{C}$ 熱処理武料の回折パターン図 では $\mathrm{MOO}_{2.8}$ のピークが消えて，新たに $\mathrm{MO}_{9} \mathrm{O}_{28}$ の回折ピー クが $\mathrm{MOO}_{3}$ の回折ピークと共に現れた。

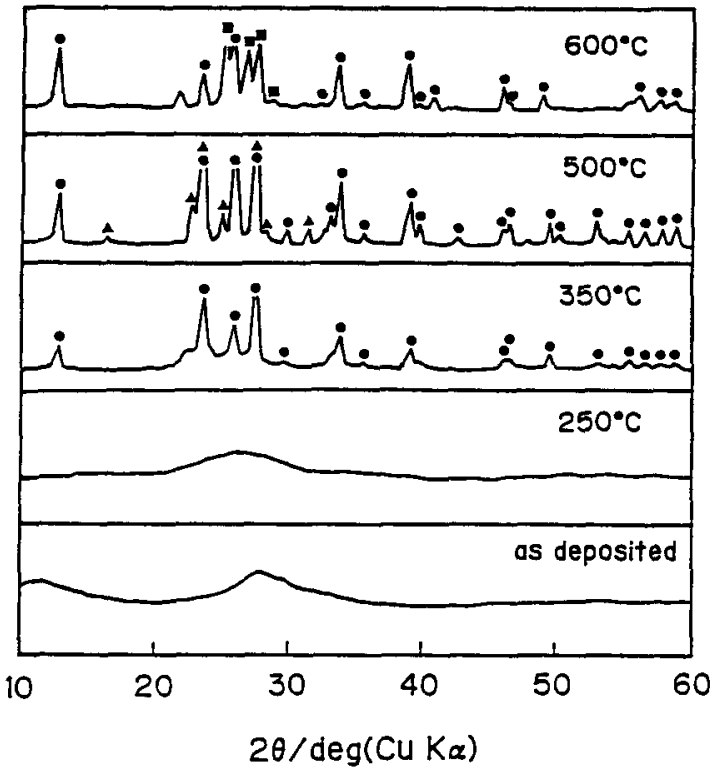

Fig.3 X-ray diffraction patterns of the electrodeposits from $\mathrm{Li}_{2} \mathrm{MoO}_{4}$ aqueous solution adjusted at pH 1 by $\mathrm{H}_{2} \mathrm{SO}_{4}$.

$$
\text { ; } \mathrm{MoO}_{3}, \triangle ; \mathrm{MoO}_{2}, 8, \mathbf{\square} ; \mathrm{MO}_{9} \mathrm{O}_{28}
$$

\section{4 定量分析}

各热処理温度での霓着物のリチウム, モリブデン, 酸 秦の定旦結果と実駼式を Table 2に示した. 何の処理も していない電着物の組成はモリブデン原子 1 に対して酸 絜5.9,リチウムは0.1であった。また, モリブデン, 酸 秦，リチウムの3種で全体量の97.9\%を占めており，電 着物はほとんどこの3程の元莱から成っていることがわ かった。これを $250^{\circ} \mathrm{C}$ 熱処理するとリチウム量に変化は ないが, 酸素はモリブデン原子 1 に対して3.3と大きく 减少した。 $350^{\circ} \mathrm{C}$ 以上の䓡処理ではそれほど大きな変化 はなくモリブデン原子 1 に対して䤕菜は約 3，リチウム は0.1であった。

Table 2 The results of elementary analys is of the electrodeposits after each heat treatment and their eapirical formulae.

\begin{tabular}{|c|c|c|c|c|c|}
\hline \multirow[t]{2}{*}{ Tenperature } & \multicolumn{4}{|c|}{ analytical results } & \multirow[t]{3}{*}{ Eupirical formula } \\
\hline & $\mathbf{L} \mathbf{i}$ & Mo & 0 & Total & \\
\hline$T / 2 \mathrm{C}$ & \multicolumn{4}{|c|}{ /wtz } & \\
\hline as deposited & 0.2 & 49.4 & 48.3 & 97.9 & 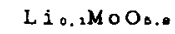 \\
\hline 250 & 0.3 & 63.7 & 35.0 & 99.0 & $\mathrm{Li}$. ${ }_{2 .} \mathrm{MoO}_{3.3}$ \\
\hline 350 & 0.3 & 64.3 & 32.7 & 97.3 & Li $0.1 \mathrm{M}_{0.0}$ \\
\hline 500 & 0.2 & $B 6.0$ & 34.2 & 100.4 & $\mathrm{Li}_{0.2} \mathrm{MoO}_{3.2}$ \\
\hline 800 & 0.4 & 66.2 & 34.5 & 101.1 & Li $0.2 \mathrm{MOO}_{3.2}$ \\
\hline
\end{tabular}




\section{4. 考実}

Table 2 より，恶盖物の出時の組成はLi。.1 $\mathrm{MoO}_{5.8}$ であるが, Fig.2のI R吸収スペクトルに見られるよう に㕣羊物は水を含んでおり，水の中に含まれる醊基がこ の分析值に現れていると考えられる.Fig.1のT G-D T A曲綜による $200^{\circ} \mathrm{C}$ 付近までの変化は試料の14.2\%の重

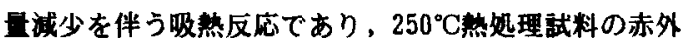
緗吸收スペクトルでは水に起因する吸収の減少がみられ、 定量分析では毁素量が成少し，X線回折では八ローパ夕 ーンを示しアモルファスであった。これらのことから $250^{\circ} \mathrm{C}$ 以下の変化電福物からの脱水によるものと考え られる、ここでの吸第ビークはブロードで重量減少も連 䌇的なことから，ここでは吸着水が脱水していると思わ

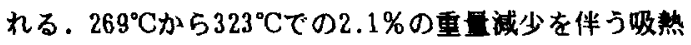
反応は, $350^{\circ} \mathrm{C}$ 熱処理試料の定量分析 (Table 2)から酸 秦量の減少，赤外線吸収スペクトル(Fig.2)から $5 \mathrm{H}_{2} \mathrm{O} に$ 起 因する吸収ピークの娍少が見られ，狭い温度籍用で起こ っていることからここでは結合水の脱水が起こっている と考えられる. $350^{\circ} \mathrm{C}$ 熱処理試料のX緗回折パターンで は $\mathrm{MoO}_{3}$ の回折ピークが現れることから $292^{\circ} \mathrm{C}$ 発热ピーク は $\mathrm{KOO}_{3}$ の晶出によるものと思われる. $500^{\circ} \mathrm{C}$ 熱処理試料

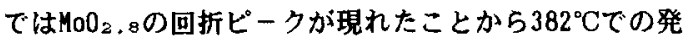
整ピークは $\mathrm{MOO}_{2.8}$ の晶出によるものと考えられる. 562

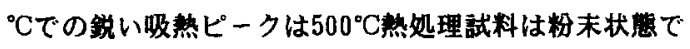
あるのに対し，600 ${ }^{\circ} \mathrm{C}$ 愁処理武料は顆粒状となったため 武料の一部堀解が起こったものと思われる．さらに700

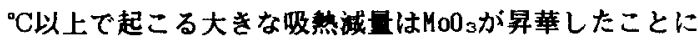
よるものと考えられる。

\section{5.管 而}

電着物は何の処理をしないものでも Li，Mo，0の3元 秦で全体の約98\%を占め,アモルファスで水を含み，Li

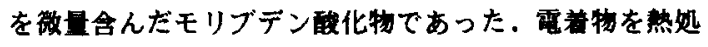
理していくと，200年付近までに吸着水の脱水が起こり， $300^{\circ} \mathrm{C}$ 付近では結合水の脱水が起こった。これらのこと からすべての水がなくなったと考えられる350 ${ }^{\circ} \mathrm{C}$ 热処理 試料で，組成はLi。.11003.。となった。これはLiを放量 含み，わすかに遇元された $\mathrm{MOO}_{3}$ と考えることができ，こ の堨合のMOの俩数は+5.9と計策される、このことは䌇く 熱処理による大部分か $\mathrm{MoO}_{3}$ として晶出することや700足 以上で試料の大部分が抟華することおよび前報てでの蛋

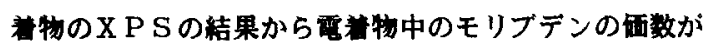
ほとんど 6 面の状息であったこととも一致する， $\mathrm{MoO}_{3}$ の エレクトロクロミズムではW03と同粎に理子とカチオン のタブルインジェクションによって式（1）のように若 消色が起こる ${ }^{17)}$ と考えられており，湆首物の組成 $\mathrm{Li}_{\mathrm{x}} \mathrm{HoO}_{3}$ は $\mathrm{MOO}_{3}$ のレクトロクロミズムにおいて育く普
色した状息に相当する。

$$
\begin{aligned}
& \mathrm{MoO}_{3}+\mathrm{x} \mathrm{Li}^{+}+\mathrm{xe}^{-} \leftarrow-\rightarrow \rightarrow \mathrm{Li}_{x} \mathrm{MOO}_{3} \\
& \text { （第色） (盘色) }
\end{aligned}
$$

このため䨘着物は，基本的には $\mathrm{MoO}_{3} と$ 考えられ，一部 のモリブデン原子が㝵元され，5洒と6伍の混合原子偭 状舁にあるため青く着色している状態で析出していると 考えられた。

\section{女}

1）吉野隆子，馬堨宣良，古宇田康雄；表面科学， 6 , 198 (1985)

2) T. Yoshino, N. Baba, Y. Kouda; Japn.J.Appl. Phys., 26, 782 (1987)

3）吉野隆子，馬場宣良，渡辺诚一；表面技術， $40 ， 42$ (1989)

4) D.Tench, L.F.Warren; J.Electrochea. Soc., 130, 869 (1983)

5) Yih-Wen, D. Chen, R.F. Nouf i; J. El ectrochen. Soc. , 131, 1447 (1984)

6) S. Mor isaki , K. Kawaka i , N. Baba; Japn.J.Appl. Phys., 27, 314 (1988)

7) 西山直捯, 森崎重吾, 馬場宣良; 電気化学, 56 , 985 (1988)

8) P.Lagrange, J.P.Schwing; Bull .Soc.Chim. France, 536 (1968)

9）東敬，福帛久哲，神田雅夫; 日本鉱羓会誌， 92, 561 (1976)

10) D.P. Anderson, L.F. Warren; J.Electrochem .Soc., 131, 347 (1984)

11) A.T. Vasko, V.P. Shaturskaia,G.S.Sewe; Ukra in.Khim. Zhur. , 40, 812 (1974)

12）東敬，福岛久哲，高松恵二，大橎秀次; 日本鏣菜会 誌, 95, 467 (1979)

13) T. Yoshino, N. Baba, K. Arai ; Japn. J. Appl.Phys., 26, 1547 (1987)

14）吉野隆子，馬堨宣良，保田宏一；日本化学会誌， 1525 (1988)

15）西山亩樹，森崎重业，馬埸宣良；表面技術， 40 , 146 (1989)

16) R.A.Nyquist, R.0.Kagel, Infrared spectra of inorganic compounds, Acadewic press, New York and London (1971)

17) R.J.Colton, A.M.Guzman, J.W. Rabalais; J. Appl .Phys., 49, 409 (1978) 